\title{
Encefalopatía necrotizante aguda asociada a influenza A
}

\section{Influenza A-associated acute necrotizing encephalopathy}

\author{
Elizabeth Muñoz-Osores ${ }^{\mathrm{a}}$, Natali Sánchez Ortiz ${ }^{\mathrm{b}}$, Max Andresen Vásquez ${ }^{\mathrm{c}}$, \\ Daniela Ávila-Smirnow ${ }^{\mathrm{d}}$, Patricio Valle Muñoz ${ }^{\mathrm{e}}$, José Barriga Gonzaga ${ }^{\mathrm{e}}$
}

\begin{abstract}
aResidente de Pediatría, División de Pediatría, Escuela de Medicina, Pontificia Universidad Católica de Chile. Santiago, Chile. besidente de Neurología Pediátrica, Unidad de Neurología Pediátrica, División de Pediatría, Escuela de Medicina, Pontificia Universidad Católica de Chile. Santiago, Chile.

'Residente de Radiología, Unidad de Radiología, Pontificia Universidad Católica de Chile. Santiago, Chile.

¿Unidad de Neurología Pediátrica, División de Pediatría, Escuela de Medicina, Pontificia Universidad Católica de Chile. Santiago, Chile.

eUnidad de Paciente Crítico Pediátrico, División de Pediatría, Escuela de Medicina, Pontificia Universidad Católica de Chile. Santiago, Chile.
\end{abstract}

Recibido: 5 de mayo de 2020; Aceptado: 15 de julio de 2020

¿Qué se sabe del tema que trata este estudio?

Encefalopatía necrotizante aguda es una patología rara, con alteraciones distintivas en neuroimágenes, asociada a alta letalidad e importantes secuelas. No existe consenso sobre su tratamiento, y hay escasa información sobre la evolución a largo plazo de estos pacientes.
¿Qué aporta este estudio a lo ya conocido?

Reportamos el caso de un paciente diagnosticado con encefalopatía necrotizante aguda asociado a influenza-A. Nuestro paciente fue manejado con terapia inmunomoduladora y antiviral de forma precoz, presentando evolución neurológica favorable. Este manejo podría ser considerado como una alternativa válida de tratamiento.

\section{Resumen}

La encefalopatía necrotizante aguda (ENA) es una patología rara, caracterizada por compromiso de conciencia y presencia de múltiples lesiones encefálicas simétricas localizadas principalmente en tálamo. Se asocia a alta letalidad e importantes secuelas. Objetivo: Describir el caso de un paciente escolar con ENA asociada a influenza-A con evolución favorable. Caso Clínico: Paciente de 6 años de edad, con historia de 3 días de evolución de síntomas respiratorios altos asociados a fiebre $\left(39^{\circ} \mathrm{C}\right)$. Veinticuatro horas previo a la consulta destacaba compromiso de conciencia cualicuantitativo. Se realizó punción lumbar con proteinorraquia leve. En resonancia magnética (RM) se identificó focos de restricción a la difusión bilaterales de distribución simétrica, talámicos, en cuerpos mamilares, periacueductales, de tegmento pontino, hipocampales y en ambas cápsulas externas, asociado a componente hemorrágico y edema vasogénico, sugerente de ENA. Recibió tratamiento empírico con metilprednisolona y oseltamivir. Posteriormente, se recibió resultado positivo para virus influenzaAH1. Dado diagnóstico, se decidió administrar inmunoglobulina, evolucionando lento pero favorablemente. Al alta levemente bradipsíquico, con disminución de agudeza visual, lenguaje espontáneo

Palabras clave:

Encefalitis Necrotizante Aguda;

Influenza A;

Niños 
y marcha con apoyo. A los 6 meses de seguimiento presentaba lenguaje y marcha normales, persistiendo alteración visual a derecha. Conclusión: Nuestro paciente presentó una ENA cuyo diagnóstico y manejo oportunos se asociaron a una favorable evolución neurológica en el largo plazo. Si bien la ENA es una patología infrecuente, la morbimortalidad asociada es altísima, por lo que resulta de gran importancia tener un alto grado de sospecha, a fin de solicitar estudio imagenológico dirigido, buscar causas infecciosas relacionadas e iniciar un manejo oportuno.

\section{Keywords:}

Acute Necrotizing

Encephalitis;

Influenza A;

Children

\section{Introducción}

La encefalopatía necrotizante aguda (ENA) es una patología rara, descrita por primera vez en 1995 por Mizuguchi et al., como una forma distintiva de encefalopatía aguda. La mayoría de los casos se han descrito en población japonesa y taiwanesa, pero cada vez se ha encontrado más en población occidental ${ }^{1}$.

El curso clínico de la ENA es grave, describiéndose 3 etapas: prodrómica, encefalopatía aguda y etapa de recuperación. En la primera etapa, los síntomas incluyen desde fiebre, síntomas respiratorios y gastrointestinales, hasta shock y falla multiorgánica. Posteriormente, se desarrolla la encefalopatía, con manifestaciones de disfunción cerebral (crisis epilépticas hasta en 40\% de los casos). Los pacientes que logran sobrevivir pasan a una etapa de recuperación, y la mayoría evoluciona con secuelas neurológicas ${ }^{2}$.

En imágenes diagnósticas se caracteriza por la presencia de múltiples lesiones inflamatorias simétricas principalmente en el tálamo, pero también en putamen, sustancia blanca cerebral y cerebelosa y en el tegmento del tronco encefálico ${ }^{2}$. Su fisiopatología no es del todo clara, y se ha asociado a factores infecciosos (virales principalmente), genéticos (RANBP2 y CPTII) y medioambientales ${ }^{3}$.

Hasta hoy en día, la mayoría de los casos reportados son de origen asiático, con muy escasa publicación pediátrica a nivel latinoamericano ${ }^{2}$. En Chile, sólo hay escasos reportes en congresos y un caso pediátrico publicado en el año 2010, correspondiente a un paciente de 7 años con muerte encefálica en contexto de ENA asociada a influenza $\mathrm{A}^{4}$.

El objetivo del presente reporte consiste en describir el caso de un paciente escolar con ENA asociada a influenza A, su manejo y la favorable evolución que presentó.

\section{Caso Clínico}

Escolar de sexo masculino de 6 años, sin antecedentes mórbidos relevantes, con desarrollo psicomotor adecuado y esquema de vacunación al día. Cursó cuadro de tres días de evolución, inicialmente de síntomas respiratorios altos asociados a fiebre hasta $39^{\circ} \mathrm{C}$, agregándose al segundo día decaimiento y preguntas reiterativas. Veinticuatro horas previo a la consulta 
destacó compromiso de conciencia cualicuantitativo, sin lograr apertura ocular, refiriendo mareos e imposibilidad para caminar. Emitía lenguaje repetitivo, e impresionaba bradipsíquico y desconectado del medio. En la evaluación del Servicio de Urgencias los exámenes generales no presentaron alteraciones. La tomografía computada de cerebro (al tercer día del cuadro) fue descrito con engrosamiento mucoso-etmoidal y maxilar bilateral, sin otros hallazgos. Se realizó punción lumbar, obteniéndose líquido cefalorraquídeo (LCR) incoloro, con leve aumento de las proteínas $(49 \mathrm{mg} /$ dl), glucorraquia $49 \mathrm{mg} / \mathrm{dl}$, sin leucocitos ni hematíes. Gram sin bacterias. El estudio toxicológico en orina fue negativo, y el Test pack para virus respiratorio sincicial, adenovirus, influenza A y B tuvo resultado negativo.

$\mathrm{Al}$ ingreso a la Unidad de Paciente Crítico el paciente no lograba apertura ocular, obedecía parcialmente las órdenes verbales, localizaba dolor y emitía sonidos ininteligibles. Al examen neurológico destacaba pupilas isocóricas y reactivas, disminución de la agudeza visual y ptosis palpebral derecha, con oculomotilidad conservada, hipertonía e hiperreflexia generalizada, plantares extensores bilaterales, clonus agotable bilateral y temblor de intención y de reposo en extremidades superiores. Se inició tratamiento con vancomicina, ceftriaxona, aciclovir, en espera de cultivos, en contexto de sospecha de meningoencefalitis sin poder descartar causa infecciosa. Se realizó electroencefalograma (EEG) que fue informado como normal, con temblor sin correlato eléctrico. La resonancia magnética (RM) más angiorresonancia de encéfalo (al cuarto día del cuadro) demostró focos de restricción a la difusión bilaterales, con distribución simétrica en talámos, cuerpos mamilares, periacueductales, de tegmento pontino, hipocampales y en ambas cápsulas externas, con componente hemorrágico, e imágenes sugerentes de edema vasogénico en hipotálamo y esplenio del cuerpo calloso (figura 1). La RM de médula espinal fue informada sin hallazgos patológicos.

Los hallazgos de la RM cerebro fueron compatibles con ENA, por lo que se controló estudio LCR, descartándose compromiso infeccioso activo, y se decidió agregar a terapia metilprednisolona $(30 \mathrm{mg} / \mathrm{kg} /$ día por 3 días) y oseltamivir de forma empírica. Se solicitó además estudio de amebas de vida libre y rabia en LCR, y se inició terapia antifúngica asociada con anfotericina deoxycolato, azitromicina, fluconazol y rifampicina, que fueron suspendidos a las $48 \mathrm{~h}$ por informes negativos. Adicionalmente, a las $72 \mathrm{~h}$ se obtuvieron cultivos de LCR, hemocultivo, urocultivo, y estudio para citomegalovirus, virus Epstein Barr, virus herpes simple y parvovirus, todos negativos, suspendiendo el tratamiento con vancomicina, ceftriaxona y aciclovir. Se decidió mantener sólo oseltamivir por cinco días en contexto de panel por PCR para virus respiratorios positivo para influenza $\mathrm{A}$.

A las $72 \mathrm{~h}$ del ingreso se controló EEG con actividad lenta difusa generalizada, compatible con su encefalopatía, pero sin crisis epilépticas. Nunca presentó compromiso respiratorio, manteniéndose siempre sin requerimientos de oxígeno suplementario ni apoyo ventilatorio. Tampoco presentó compromiso esfinte-

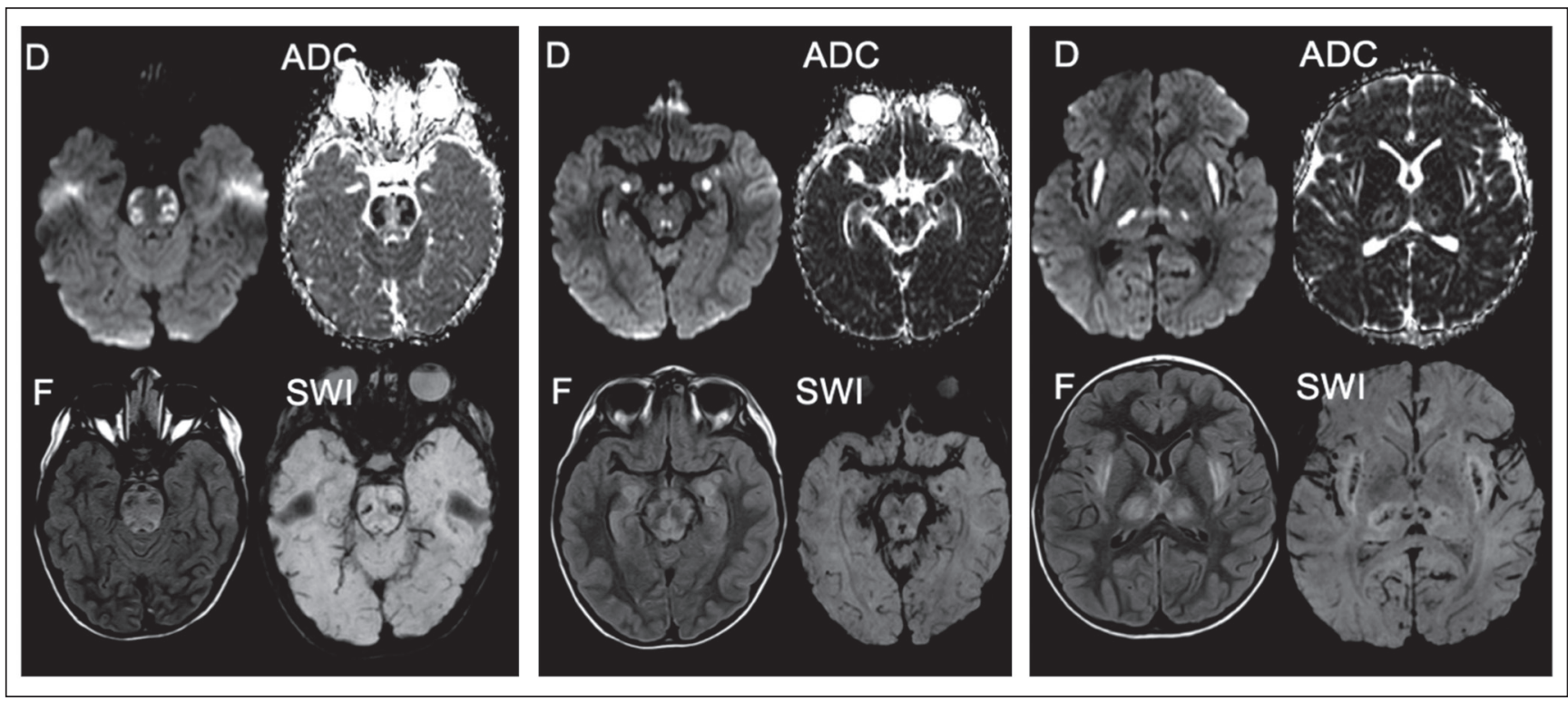

Figura 1. Focos de restricción a la difusión bilaterales de distribución simétrica talámicos, cuerpos mamilares, periacueductales, de tegmento pontino, hipocampales y en ambas cápsulas externas. Se asocia a componente hemorrágico en estas regiones (SWI). Lo anterior, asociado a hiperseñal en F en estas regiones, incluyendo región hipotalámica y esplenio del cuerpo calloso, explicado por edema vasogénico. D (DWI); $A D C$ (coeficiente de difusión aparente); F (FLAIR); SWI (secuencias de susceptibilidad magnética). 
riano ni crisis epilépticas durante su estadía en UCI. Desde el punto de vista nutricional, requirió alimentación progresiva vía sonda nasoyeyunal desde el segundo día de su ingreso. Los controles de exámenes generales no evidenciaron compromiso de otros órganos. Evolucionó con importante alteración en la agudeza visual bilateral, bradipsíquico, sin emitir lenguaje claro y con síntomas piramidales. Por lo anterior, al séptimo día de evolución, se decidió iniciar segunda línea de tratamiento, con gammaglobulina $400 \mathrm{mg} / \mathrm{kg} / \mathrm{día}$ por 5 dosis.

Finalmente completó curso de metilprednisolona, gammaglobulina y oseltamivir, manteniendo terapia con prednisona ( $1 \mathrm{mg} / \mathrm{kg} / \mathrm{día})$. Evolucionó de manera favorable, con cambios objetivados aproximadamente cada 48 h. Fue dado de alta luego de 17 días de hospitalización, presentando mejor contacto con el medio, aún bradipsíquico pero logrando lenguaje espontáneo inteligible. Logró realimentarse por boca previo al alta. Destacó, además, alteración de la agudeza visual bilateral y compromiso motor grueso y fino, disminuyendo paulatinamente los síntomas piramidales, y logrando marcha con apoyo.

En el seguimiento se mantuvo en rehabilitación multidisciplinaria, observándose recuperación progresiva de funciones neurológicas. Se realizó tratamiento esteroidal en dosis inicial durante 3 meses, con suspensión gradual en forma posterior, sin presentar recaídas. A los 6 meses de evolución, el paciente logró reincorporarse a educación formal, con adecuaciones curriculares. En la última evaluación clínica su lenguaje era normal, estaba iniciando lectoescritura, presentaba hiperreflexia de extremidades inferiores, dismetría de extremidades superiores y marcha normal. Desde el punto de vista neuroftalmológico, tuvo disminución severa de la agudeza visual del ojo derecho.

\section{Discusión}

La ENA es una enfermedad rara, de incidencia desconocida. En un estudio epidemiológico de Japón, se reportó una incidencia de 4\% (39 pacientes) de un total de 983 pacientes pediátricos con algún tipo de encefalopatía aguda ${ }^{5}$. Los reportes de letalidad informan hasta un 30\%, y de graves secuelas neurológicas hasta en un $15 \%$ de los sobrevivientes 6 .

Su etiopatogenia hasta ahora no es clara. Ciertos estudios indican que ante la presencia viral, se desencadena una "tormenta de citoquinas" proinflamatorias, como IL-6 y TNF- alfa ${ }^{7}$. Esto produce una destrucción proteolítica de la barrera hematoencefálica con aumento de la permeabilidad vascular, que causa edema cerebral, hemorragia petequial y necrosis ${ }^{8,9}$.

En los últimos años se ha establecido una forma fa- miliar y recurrente de ENA, asociada a alteraciones en el gen RANBP2, con herencia autosómica dominante, de penetrancia incompleta. Dicho gen codifica la proteína del complejo del poro nuclear la RAN binding protein 2, importante para la función neuronal ${ }^{10}$. Sin embargo, se han descrito casos de recurrencia, sin alteración del gen $R A N B P 2$, como aquellos pacientes con deficiencia de CPTII, que presentan una infección viral, desarrollan falla energética y presentan un curso clínico de ENA ${ }^{11}$.

Los criterios diagnósticos de Mizuguchi et al., incluyen: encefalopatía aguda luego de una enfermedad viral febril, con rápido deterioro del nivel de conciencia; aumento de proteínas en LCR, sin pleocitosis; hallazgos patognomónicos en RM de cerebro; elevación de aminotransferasas sin hiperamonemia; exclusión de otras enfermedades que expliquen el cuadro (como meningitis viral o bacteriana, hepatitis fulminante, síndrome de Reye, etc. $)^{12}$. El hallazgo imagenológico más característico es el compromiso inflamatorio simétrico y bilateral del tálamo, que puede asociarse a lesiones en los putamenes, sustancia blanca cerebral y cerebelosa y en tegmento del tronco encefálico ${ }^{12}$. La imagen clásica de ENA es el patrón "tricolor" o "trilaminar" en el tálamo y se observa en secuencias de coeficiente de difusión aparente. La apariencia trilaminar se caracteriza por una capa interna de restricción facilitada por hemorragia-necrosis (iso-hiperintenso), seguido por una zona con restricción a la difusión por edema citotóxico (hipointenso) y una porción externa con restricción facilitada por edema vasogénico (hiperintenso $)^{13}$. La RM de nuestro paciente presentó hallazgos consistentes con ENA, la clínica fue compatible con encefalopatía aguda, y se descartaron otras enfermedades que explicaran el cuadro, concordantes con estos criterios.

Hasta ahora no existe una terapia demostrada. Los reportes y estudios proponen manejo sintomático, terapia antiviral empírica (oseltamivir), agentes inmunomoduladores e hipotermia ${ }^{6}$. Sin embargo, no se han descrito pautas de tratamiento y no hay consenso sobre la utilidad real de estas terapias. Algunos estudios han reportado que la administración de esteroides dentro de las $24 \mathrm{~h}$ posteriores al inicio o en la etapa temprana de la enfermedad estaría relacionada con un mejor pronóstico en las personas sin compromiso del tronco encefálico ${ }^{14}$. Sin embargo, hay reportes que plantean administración de esteroides en cualquier etapa, y otros que han concluido que no influirían en la evolución de la enfermedad ${ }^{15}$.

Dado la fisiopatología del ENA, se han propuesto uso de terapias contra la tormenta citoquímica que se produce, como el uso de bloqueadores de receptores de IL-6 (tocilizumab), administrados en períodos precoces de la enfermedad, con buenos resultados en el 
pronóstico a corto y largo plazo $^{16}$. En este caso, nuestro paciente fue tratado con corticoides y oseltamivir, agregándose posteriormente inmunoglobulina a la terapia, con respuesta lenta pero favorable. Este manejo fue similar al descrito en un artículo en el año 2006, que describe el caso de un niño de 3 años sin factor desencadenante identificado, tratado con inmunoglobulina y metilprednisolona, que evolucionó con mejoría marcada de ataxia, espasticidad y disartria ${ }^{17}$. Sin embargo, cabe destacar que en un estudio publicado en 2015, se analizaron los factores asociados al pronóstico en niños con ENA, concluyendo que la modalidad de tratamiento no afectaba el resultado de estos pacientes (incluyendo pulsos de metilprednisolona e inmunoglobulina $)^{18}$.

El pronóstico de ENA es variable, la recuperación es lenta y se ha descrito que menos de $10 \%$ de los pacientes tiene una recuperación completa, con una letalidad de $30 \%$, asociada principalmente a edema cerebral en algunos reportes ${ }^{4,15}$. El principal factor asociado a mortalidad descrito es el compromiso del tronco encefáli$\mathrm{Co}^{15}$. Dentro de los indicadores de buen pronóstico se reportan: edad menor de 4 años, hiperproteinorraquia leve, compromiso unilateral de tálamo, ausencia de compromiso de troncoencéfalo, reversión completa de las lesiones en neuroimagen y escala de severidad de ENA de bajo riesgo ${ }^{18}$. La presencia de shock al ingreso, edad mayor a 4 años y la identificación de lesiones en tronco encefálico en las neuroimágenes se asociaron significativamente a mal outcome neurológico ${ }^{18}$. Pese a que nuestro paciente no cumplía criterios de buen pronóstico, su evolución fue muy favorable comparativamente a lo reportado en la literatura. Esto podría deberse al acceso oportuno de neuroimágenes y especialistas que pudieron realizar un diagnóstico precoz, iniciando las opciones terapéuticas disponibles en los primeros días del cuadro. Sin embargo, falta evidencia que nos permita dilucidar qué otros factores podrían haber influido en la evolución favorable de nuestro paciente.

\section{Conclusiones}

La ENA es una patología infrecuente, de diagnóstico clínico-radiológico. Resulta de gran importancia sospecharla precozmente, solicitar las imágenes pertinentes en búsqueda de los hallazgos característicos asociados, e investigar causas infecciosas relacionadas. Su morbimortalidad asociada es altísima, y no hay evidencia concluyente en relación a su tratamiento. La terapia antiviral empírica y los inmunomoduladores podrían ser propuestos como alternativas válidas de tratamiento.

Se necesitan más estudios para poder orientar el manejo diagnóstico-terapéutico, sin embargo, este reporte de caso podría ser utilizado como experiencia para el enfrentamiento inicial.

\section{Responsabilidad Éticas}

Protección de personas y animales: Los autores declaran que los procedimientos seguidos se conformaron a las normas éticas del comité de experimentación humana responsable y de acuerdo con la Asociación Médica Mundial y la Declaración de Helsinki.

Confidencialidad de los datos: Los autores declaran que han seguido los protocolos del centro de trabajo sobre la publicación de datos de pacientes.

\section{Derecho a la privacidad y consentimiento informa-} do: Los autores han obtenido el consentimiento informado de los pacientes y/o sujetos referidos en el artículo. Este documento obra en poder del autor de correspondencia.

\section{Conflicto de intereses}

Los autores declaran no tener conflicto de intereses.

\section{Referencias}

1. Mizuguchi M, Abe J, Mikkaichi K, et al. Acute necrotising encephalopathy of childhood: a new syndrome presenting with multifocal, symmetric brain lesions. Journal of Neurology, Neurosurgery, and Psychiatry 1995;58(5):555-61. Retrieved from http://www.ncbi.nlm.nih. gov/pubmed/7745402\%0Ahttp://www. pubmedcentral.nih.gov/articlerender. fcgi? artid=PMC1073485.

2. Ssaab S, Torres JB, Serrano S, Rodríguez N. Encefalopatía necrotizante aguda de la infancia. Acute Necrotizing Encephalopathy of Childhood. Diagnosis. 2015;26(2):4223-7.

3. Shinohara M, Saitoh M, Takanashi J, et al. Carnitine palmitoyl transferase II polymorphism is associated with multiple syndromes of acute encephalopathy with various infectious diseases. Brain and Development, 2011;33(6):512-7. https:// doi.org/10.1016/j.braindev.2010.09.002.

4. Bustos BR, Andrade YF. Encefalopatía aguda y muerte encefálica en un niño con influenza A (H1N1) 2009 durante la primera ola pandémica. Revista Chilena de
Infectología. 2010;27(5):413-6. https:/doi. org/10.4067/s0716-10182010000600007.

5. Hoshino A, Saitoh M, Oka A, et al. Epidemiology of acute encephalopathy in Japan, with emphasis on the association of viruses and syndromes. Brain and Development. 2012;34(5):337-43. https:// doi.org/10.1016/j.braindev.2011.07.012.

6. Wu X, Wu W, Pan W, Wu L, Liu K, Zhang H-L (2015a). Acute Necrotizing Encephalopathy: An Underrecognized Clinicoradiologic Disorder. Mediators of Inflammation. 2015;1-10. https://doi. org/10.1155/2015/792578. 
7. Ito $\mathrm{Y}$, Ichiyama $\mathrm{T}$, Kimura $\mathrm{H}$, et al. Detection of influenza virus RNA by reverse transcription-PCR and proinflammatory cytokines in influenzavirus-associated encephalopathy. Journal of Medical Virology. 1999;58(4):420-5. https://doi.org/10.1002/(SICI)10969071(199908)58:4<420::AIDJMV16>3.0.CO;2-T

8. Ichiyama T, Endo $S$, Kaneko M, Isumi H, Matsubara T, Furukawa S. Serum cytokine concentrations of influenza-associated acute necrotizing encephalopathy. Pediatrics International. 2003;45(6):734-6. https://doi.org/10.1111/ j.1442-200X.2003.01822.x.

9. Kansagra SM, Gallentine WB. Cytokine storm of acute necrotizing encephalopathy. Pediatric Neurology. 2011;45(6):400-2. https://doi. org/10.1016/j.pediatrneurol.2011.09.007.

10. Neilson DE, Adams MD, Orr CMD, et al. Infection-Triggered Familial or Recurrent Cases of Acute Necrotizing Encephalopathy Caused by Mutations in a Component of the Nuclear Pore,
RANBP2. American Journal of Human Genetics. 2009;84(1):44-51. https://doi. org/10.1016/j.ajhg.2008.12.009.

11. Chen Y, Mizuguchi H, Yao D, et al. Thermolabile phenotype of carnitine palmitoyltransferase II variations as a predisposing factor for influenzaassociated encephalopathy. FEBS Letters. 2005;579:2040-4. https://doi. org/10.1016/j.febslet.2005.02.050.

12. Mizuguchi M. Acute necrotizing encephalopathy of childhood: a novel form of acute encephalopathy prevalent in Japan and Taiwan. Brain and Development. 1997;19:81-92.

13. Wu X, Wu W, Pan W, Wu L, Liu K, Zhang H-L. (2015b). Acute Necrotizing Encephalopathy: An Underrecognized Clinicoradiologic Disorder. Mediators of Inflammation. 2015;1-10. https://doi. org/10.1155/2015/792578.

14. Okumura A, Mizuguchi M, Kidokoro $\mathrm{H}$, et al. Outcome of acute necrotizing encephalopathy in relation to treatment with corticosteroids and gammaglobulin. Brain and Development. 2009;31(3):221-
7. https://doi.org/10.1016/j.

braindev.2008.03.005.

15. Lee CG, Kim JH, Lee M, Lee J. Clinical outcome of acute necrotizing encephalopathy in related to involving the brain stem of single institution in Korea. Korean journal of pediatrics. 2014;57(6):264.

16. Koh JC, Murugasu A, Krishnappa J, Thomas T. (2019). Favorable Outcomes With Early Interleukin 6 Receptor Blockade in Severe Acute Necrotizing Encephalopathy of Childhood. Pediatric Neurology. https://doi.org/10.1016/j. pediatrneurol.2019.04.009.

17. Manara R, Franzoi M, Cogo P, Battistella PA. Acute necrotizing encephalopathy: combined therapy and favorable outcome in a new case. Child's Nervous System. 2006;22(10):1231-6.

18. Yamamoto H, Okumura A, Natsume J, Kojima S, Mizuguchi M. A severity score for acute necrotizing encephalopathy. Brain and Development. 2015;37(3):3227. https://doi.org/10.1016/j. braindev.2014.05.007. 